\title{
Value of computerised tomography in children with non-specific mental subnormality
}

\author{
SUNDARA LINGAM, SUSAN READ, IAN M HOLLAND, JOHN WILSON, \\ EDWARD M BRETT, AND RICHARD D HOARE
}

The Hospital for Sick Children, London

SUMMARY Seventy-six children had computerised tomography scans as part of an investigation of mental subnormality; most of them are severely retarded and all those over age 5 years attend special schools. Seventy-two per cent of the children had normal scans. Twenty per cent showed cerebral atrophy and in only $8 \%$ was there a specific abnormality (agenesis of corpus callosum, arachnoid cyst, communicating hydrocephalus). None of these findings had any positive prognostic implication. Sedation or general anaesthesia was required for all except one child. Injection pethidine compound was used for children under age 5 years or less than $30 \mathrm{~kg}$ in weight, and trimeprazine orally was used for older children. The radiation exposure was high- $5.6 \mathrm{rad}$ per scan, which is 100 times greater than that from a posteroanterior and lateral chest $x$-ray film. For these reasons computerised tomography scans cannot be recommended as a routine part of the investigation of children with non-specific mental subnormality.

The technique of computerised tomography (CT) was introduced in 1972. Before then many infants and children were subjected to lumbar air-encephalography for the investigation of epilepsy and mental retardation. Brett and Hoare, ${ }^{1}$ in a review from this hospital, found that lumbar air-encephalography was not of great help in establishing a precise diagnosis, nor was it useful in predicting the outcome of non-specific mental retardation, and with the introduction of CT here in 1977, lumbar airencephalography was abandoned for such purposes. This study is an assessment of the value of CT of the head in the investigation of mentally subnormal children.

\section{Materials and methods}

The clinical records of children with non-specific subnormality were examined and any child who also had cerebral palsy or a known cause for his mental subnormality-such as karyotype abnormalities, documented birth asphyxia, proved metabolic abnormalities, clinically obvious central nervous system malformations, or tuberous sclerosiswas excluded. Children with microcephaly (head circumference less than the 2 nd centile) or macrocephaly (head circumference above the 98th centile) were not included. There were no children with gross dysmorphic features in the series but some children with mild dysmorphic features were included-that is children with clinodactyly, single palmar creases and abnormal pinnae, or mild hypertelorism.

All the scans were reviewed by neuroradiologists and were classified as normal, cerebral atrophy, or others.

\section{Results}

The clinical records of 76 children ( 34 girls and 42 boys) were analysed. Their ages ranged from 11 months to 15 years (mean $3 \frac{1}{2}$ years). Fifty-six children were under 5 years. Every child over age 5 years was educationally subnormal (ESN) and attended a special school. Seven children attended ESN (S,

Table $1 C T$ scan findings in children with mental subnormality

\begin{tabular}{|c|c|c|c|c|c|c|}
\hline \multirow[t]{2}{*}{ Group } & \multirow[t]{2}{*}{ Number } & \multirow[t]{2}{*}{ Normal } & \multirow{2}{*}{$\begin{array}{l}\text { Cerebral } \\
\text { atrophy }\end{array}$} & \multicolumn{3}{|c|}{ Abnormal } \\
\hline & & & & $A C C$ & $A C$ & $\mathrm{CH}$ \\
\hline $\begin{array}{l}\text { Mental subnormality } \\
\text { (non-specific) }\end{array}$ & 64 & $\begin{array}{l}48 \\
(75 \%)\end{array}$ & $\begin{array}{l}12 \\
(18 \cdot 75 \%)\end{array}$ & 1 & 2 & 1 \\
\hline $\begin{array}{l}\text { Mental subnormality } \\
\text { with dysmorphic } \\
\text { features }\end{array}$ & 12 & $\begin{array}{c}7 \\
(58 \cdot 3 \%)\end{array}$ & $\stackrel{3}{(25 \%)}$ & 2 & 0 & 0 \\
\hline
\end{tabular}

ACC $=$ agenesis of corpus callosum; $\mathbf{A C}=$ arachnoid cyst ; $\mathrm{CH}=$ communicating hydrocephalus. 
Table 2 Children $(n=15)$ with cerebral atrophy in CT scan

\begin{tabular}{|c|c|c|c|c|c|c|c|c|c|}
\hline & \multirow{2}{*}{$\begin{array}{l}\text { No of } \\
\text { children }\end{array}$} & \multicolumn{2}{|c|}{ Developmental delay } & \multicolumn{2}{|l|}{ Sedation } & \multirow[t]{2}{*}{ GA scan } & \multicolumn{3}{|c|}{ Head circumference (centile) } \\
\hline & & Mild & Severe & $\begin{array}{l}\text { Pethidine } \\
\text { compound }\end{array}$ & Trimeprazine & & $2-25$ & $25-50$ & $50-98$ \\
\hline $\begin{array}{l}<5 \text { years } \\
>5 \text { years }\end{array}$ & $\begin{array}{r}11 \\
4\end{array}$ & $\begin{array}{l}6 \\
1\end{array}$ & $\begin{array}{l}5 \\
3\end{array}$ & $\frac{10}{-}$ & $\overline{2}$ & $\begin{array}{l}1 \\
2\end{array}$ & $\frac{4}{-}$ & $\begin{array}{l}5 \\
3\end{array}$ & $\begin{array}{l}2 \\
1\end{array}$ \\
\hline
\end{tabular}

GA = general anaesthesia.

Table 3 Children who had scans under sedation and general anaesthesia

\begin{tabular}{lc}
\hline $\begin{array}{l}\text { Sedation } \\
\text { Pethidine compond* }\end{array}$ & $63+$ intravenous diazepam 11 \\
& \\
Trimeprazine & 9 \\
General anaesthesia & 3 \\
Planned & 4 \\
Sedation failure & 1 \\
No sedation & \\
\hline Pethidine $25 \mathrm{mg} ;$ promethazine $6.25 \mathrm{mg}$; chlorpromazine $6.25 \mathrm{mg}$ \\
in $1 \mathrm{ml}$. Dose $0.1 \mathrm{ml} / \mathrm{kg} 45$ minutes before scanning.
\end{tabular}

severe) schools. Some of the under fives were mildly retarded but most of them were severely so, with an intelligence quotient (IQ) or developmental quotient (DQ) of below 50. Twelve of the 76 children had mild dysmorphic features.

The CT scan findings are shown in Table 1.

Fifty-five $(\mathbf{7 2} \%)$ children showed normal scans and $15(20 \%)$ showed cerebral atrophy (dilated lateral and 3rd ventricles, prominent cortical sulci, and interhemispheric fissure). If the children with mental subnormality alone are compared with those with both mental subnormality and dysmorphic features, the incidences of cerebral atrophy and normal scans do not differ appreciably.

The 15 children with cerebral atrophy were further analysed. The results are shown in Table 2 . Cerebral atrophy was present in children of all ages, being present in 3 of the 7 who had general anaesthesia and in 12 of the 72 who were sedated. The head circumferences of these children ranged between the 2 nd and 98 th centiles.

Seventy-two children had CT scans under sedation (Table 3); 63 children received injection pethidine compound (Inj. Peth-Co) and 9 were given trimeprazine (Vallergan) orally. In addition, 11 children who had pethidine compound needed intravenous diazepam because sedation was not adequate, and 1 child had brief respiratory depression during the administration of diazepam. One child did not require sedation. Seven $(9 \%)$ children had scans under general anaesthesia with no complications; in 3 cases this was a planned procedure and in 4 it was done because sedation (pethidine compound + intravenous diazepam) had failed.

\section{Discussion}

CT represents a great advance in the investigation of children with various neurological disorders and has superseded lumbar air-encephalography for most purposes. Nevertheless, because of expense and the exposure to radiation, it should not be undertaken without careful consideration.

In $15(20 \%)$ of our patients cerebral atrophy was found. This has no precise aetiological or prognostic implications and is seen in many disorders of the central nervous system both static and progressive.

Confusion may occur as 'brain shrinkage' due to fluid depletion as a result of prolonged fasting may show similar appearances. Most children are fasted for 3 hours before scanning with sedation, and for 4 hours with general anaesthesia, but sometimes for longer periods (up to 6 hours) if there is some unexpected delay in scanning.

Reversible cerebral atrophy has also been seen during treatment with steroids and corticotrophin. ${ }^{2} 3$ It must be acknowledged that we do not know if the same appearances of cerebral atrophy would be present if the scans were repeated without fasting.

Although more specific abnormalities were found in 6 children none led to surgical treatment. In 2 of the 3 children with agenesis of the corpus callosum it was thought in retrospect that the diagnosis might have been suspected because of ocular hypertelorism and a high arched palate. In the 3 other children

Table 4 Radiation risk of CT scanners (EMI Medical)*

General Purpose CT 505

Phantom scan, $140 \mathrm{kV} 28 \mathrm{~mA}, 20$ seconds, $13 \mathrm{~mm}$ slice increment $190 \mathrm{~mm}$ field

\begin{tabular}{lll} 
& \multicolumn{2}{c}{ Peak skin dose $(\mathrm{rad})$} \\
\cline { 2 - 3 } & Single scan & Multiple \\
Brain & $1 \cdot 9$ & $3 \cdot 2$ \\
Body & $1 \cdot 5$ & $3 \cdot 5$ \\
Slow scan will increase the dose & $\times 4$ & \\
Brain Scanner, CT 1010 & & \\
Phantom scan, $120 \mathrm{kV}, 33 \mathrm{~mA}$, & 60 seconds, and $20 \mathrm{~mm}$ slice increment \\
& Peak skin dose $(\mathrm{rad})$ \\
\cline { 2 - 2 } & Single scan & Multiple \\
& $(2$ slice $)$ & $(8$ slice $)$ \\
Brain & $3 \cdot 0$ & $5 \cdot 6$ \\
Slow scan will increase the dose $\times 4$ &
\end{tabular}

*Data obtained from EMI Medical-personal communication (SL) and confirmed by $\mathrm{Mr} \mathrm{K}$ Evans. 
( 2 with arachnoid cysts and one with communicating hydrocephalus) the abnormalities were unsuspected. Although 2 children had arachnoid cysts, this finding did not alter this prognosis except to suggest the the children might later develop fits.

None of these findings had any positive genetic implications. The finding of the more specific abnormalities may be helpful in suggesting a low recurrence risk. Agenesis of the corpus callosum is rarely inherited although it has been suggested that the Aicardi syndrome ${ }^{45}$ of infantile spasms, callosal agenesis, and retinal dysplasia may be inherited as an X-linked dominant lethal to hemizygous males.

CT scanning is a simple procedure and only requires the patient to lie still for about 15 minutes. Seventy-two of our 76 children had to be sedated or were even given general anaesthesia; 4 others had general anaesthesia because of sedation failure with the potential risk that this implies.

The radiation exposure in our patients was not slight. The radiation doses from CT scanning are shown in Table 4. The machine used was an EMI brain scanner, CT 1010 (8 slices) giving a peak skin radiation of 5.6 rad (EMI, 1980, personal communication). In other studies the radiation dose was considered to be higher. ${ }^{67}$ The radiation is about 20 times greater than that for a skull radiograph with 5 views for a 1 -year-old child $(0 \cdot 3 \mathrm{rad})$. This should be compared with a posteroanterior view and lateral chest $x$-ray film which gives $0.05 \mathrm{rad}$ of radiation.

We consider that CT scanning is rarely helpful in children with non-specific mental subnormality, and adds disappointingly little to the understanding of this condition. We cannot recommend it as a part of a routine investigation of children with mental subnormality.

We thank Mr Neil Picton Robinson, principal scientific officer, and $\mathrm{Mr} \mathrm{K}$ Evans, radiological protection adviser, for reviewing and discussing the radiation risks, Dr M A Preece for help with the statistics, and Dr W C Marshall for advice.

\section{References}

1 Brett E M, Hoare R D. An assessment of the value and limitations of air encephalography in children with mental retardation and with epilepsy. Brain 1969; 92: 731-42.

${ }^{2}$ Lyen K R, Holland I M, Lyen Y C. Letter: Reversible cerebral atrophy in infantile spasms caused by corticotrophin. Lancet 1979 ; ii: $37-8$.

3 Gordon N. Intractable epilepsy in childhood. Dev Med Child Neurol 1980; 22: 97-100.

4 Aicardi J, Chevrie J J, Rousselie F. Le syndrome spasmes en flexion, agénesie calleuse, anomalies chorio-rétiniennes. Arch Fr Pediatr 1969; 26: 1103-20.

5 de Jong J G Y, Delleman J W, Houben M, et al. Agenesis of the corpus callosum, infantile spasms, ocular anomalies (Aicardi's syndrome). Neurology (Minneap) 1976; 26: $1152-8$

6 Brasch R C, Boyd D P, Gooding C A. Computed tomographic scanning in children. Comparison of radiation dose and resolving power in commercial CT scanners. AJR 1978; 131: 95-101.

7 McCullough E C, Thomas Payne J T. Patient dosage in computed tomography. Radiology 1978; 129: 457-63.

Correspondence to Dr S Lingam, The Hospital for Sick Children, Great Ormond Street, London WC1N 3JH.

Received 12 October 1981 